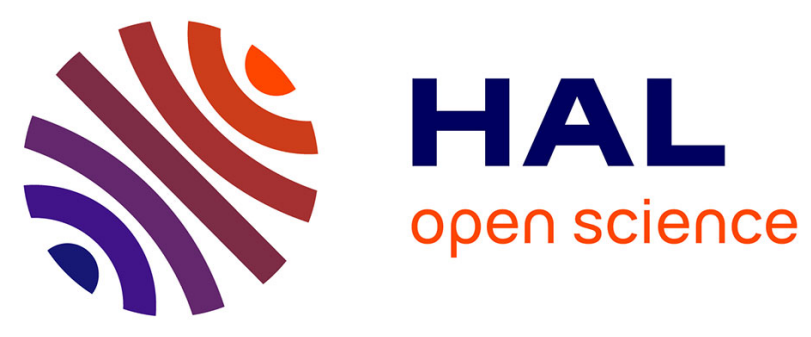

\title{
Inclusive Side-Scrolling Action Game Securing Accessibility for Visually Impaired People
}

Masaki Matsuo, Takahiro Miura, Masatsugu Sakajiri, Junji Onishi, Tsukasa Ono

\section{- To cite this version:}

Masaki Matsuo, Takahiro Miura, Masatsugu Sakajiri, Junji Onishi, Tsukasa Ono. Inclusive SideScrolling Action Game Securing Accessibility for Visually Impaired People. 16th IFIP Conference on Human-Computer Interaction (INTERACT), Sep 2017, Bombay, India. pp.410-414, 10.1007/978-3319-68059-0_41. hal-01679808

\section{HAL Id: hal-01679808 https://hal.inria.fr/hal-01679808}

Submitted on 10 Jan 2018

HAL is a multi-disciplinary open access archive for the deposit and dissemination of scientific research documents, whether they are published or not. The documents may come from teaching and research institutions in France or abroad, or from public or private research centers.
L'archive ouverte pluridisciplinaire HAL, est destinée au dépôt et à la diffusion de documents scientifiques de niveau recherche, publiés ou non, émanant des établissements d'enseignement et de recherche français ou étrangers, des laboratoires publics ou privés.

\section{(c)(1)}

Distributed under a Creative Commons Attribution| 4.0 International License 


\title{
Inclusive Side-scrolling Action Game Securing Accessibility for Visually Impaired People
}

\author{
Masaki Matsuo ${ }^{1}$, Takahiro Miura ${ }^{2}$, Masatsugu Sakajiri ${ }^{1}$, \\ Junji Onishi ${ }^{1}$, and Tsukasa Ono ${ }^{1}$ \\ 1 Tsukuba University of Technology, \\ 4-12-7 Kasuga, Tsukuba, Ibaraki 305-8521 Japan. \\ \{mm163204@g, sakajiri@cs.k, ohnishi@cs.k, ono@cs.k\}.tsukuba-tech.ac.jp \\ 2 Institute of Gerontology, the University of Tokyo, \\ 7-3-1 Hongo, Bunkyo-ku, Tokyo 113-8656, Japan. \\ miu@iog.u-tokyo.ac.jp
}

\begin{abstract}
Though many computer games have recently become accessible for gamers with visual impairments, these players still face difficulty in manipulating game characters and acquiring visual information. It is true that although an increasing number of games for visually impaired people called audio games are being developed, many of these games cannot satisfy their basic needs because of the shortage of contents and are difficult for sighted people because of no visual information. Based on this situation, we have been developing accessible games for visually impaired people that feature enriched materials and multimodal information presentation. However, the needs of real-time action on accessible games remain unsolved. In this article, our objective is to develop an inclusive side scroller game with high real-time performance and accessibility functions for visually impaired people, and be available to play with more than one person including sighted persons.
\end{abstract}

Keywords: Visually impaired people, inclusive game, side scroller games, game accessibility, auditory display, tactile display

\section{Introduction}

Computer games have become increasingly diversified. These games have been made in various formats, including commercial arcade games, consumer games, and personal computer games. The most recent games feature high-pixel density and high-definition displays, which have increased the amount of visual information that gamers receive. As a result, visually impaired and blind people frequently find it difficult to enjoy most of these games, regardless of the vast majority of research on game accessibility [1-4]. A sighted person can visually receive maps, text, and other game information. But for the visually impaired, the level of difficulty increases because of their reliance on sound information to play a game. For blind people to play independently, they need to memorize associations between the scenes and sound effects in the game. Also, they 
must remember everything from the menus and categories, and many other item orders, required to play the game. It takes extra effort on the part of visually impaired gamers to play regular games compared to the effort required of a sighted person.

In recent times, there has been progress in developing games intended for blind people. A report covering games that can be played by blind persons, on their own or with an assistance of others, was featured on the website AudioGames.net [5]. This site is a collection of information on games for the visually impaired. These games are called audio games, which the visually impaired can play using a screen reader. However, many of these games cannot satisfy the basic needs of visually impaired people because of the shortage of content and are difficult for sighted people because of no visual information.

Based on this shortage, we have been developing accessible games for visually impaired people that feature enriched materials and multimodal information presentation. We developed an action RPG (role-playing game) that visually impaired, and sighted person can play together $[6,7]$. This RPG is able to present game information acoustically, tactually, and visually. The game was released on the web and is being played by users around the world. It has undergone several upgrades to implement improvements based on user feedback which has modified the game to be more enjoyable and easier to play. However, the needs of real-time action for accessible games remains unsolved. Of course, there are some exergames that the visually impaired can play, but these exergames usually require a large space and special sensors [9-11]. Thus, it is necessary to develop an accessible real-time action game that can run without any exceptional detectors.

In this article, our objective is to develop an inclusive side-scrolling action game with a high real-time performance for not only visually impaired but also sighted computer users. This game will also allow play by more than one person without peculiar input devices.

\section{Inclusive side scroller game}

\subsection{Overview}

The screenshot of the game is shown in Fig. 1. The game we developed is a sidescrolling action game that sighted and visually impaired Windows users can play together with ordinary input devices. As is the case in the manipulations of our previous games, sighted persons control a game character with viewing information on the screen, while visually impaired persons handle a game character based on auditory information and/or tactile information. The game requires the users to recognize and judge the current game situation and to operate the

alter ego in the game more quickly and precisely. In addition, this side-scroller can have multiple players including not only sighted but also visually impaired gamers cooperatively. 


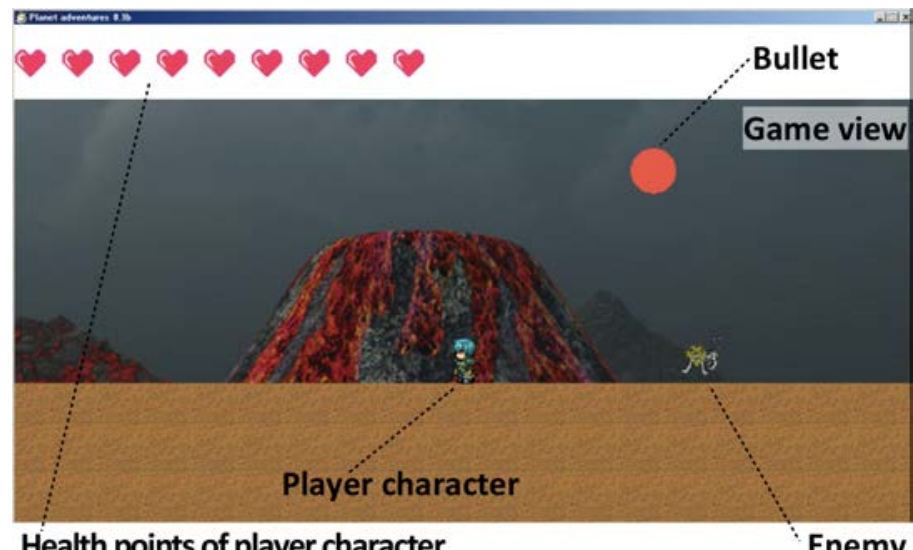

Fig. 1. A screenshot of the view of our side-scrolling action game with annotations of game elements.

\subsection{Game development environment}

We firstly prepared the game development environment for the computer user with total blindness, who is one of the authors. The programming language selected for game development using a screen reader was the Hot Soup Processor (HSP). This programming language was used to develop the game's basic algorithm. Additionally, the text and the screen displayed by the game was prepared using Otonove and AudibleMapper, which one of the authors had developed previously.

These tools were developed using the HSP and can be used even by individuals with visual impairments. Otonove makes it possible to prepare sound novel games (sound-based adventure games played primarily based on text information) by combining text information with available options as well as sound effects. AudibleMapper is a tool for creating 2D fields that support accessibility for totally blind people. It can create 2D bird's-eye fields with sound and without visual information. An example of the edited field and the corresponding game field is shown in Fig. 2.

Sound effects, background music, and graphic elements were selected from materials available on the Internet, either free or for a fee. We selected the processing methods and the allocation of background music and sound effects using free software that operates on the Windows operating system.

\subsection{Game flow}

The primary control of this game is similar to other side-scrolling games: moving the player character left or right while using jump actions and utilizing weapons to beat down enemies. The field has obstacles including walls, valleys, and enemy characters. When the character falls into a valley, the player must restart from 


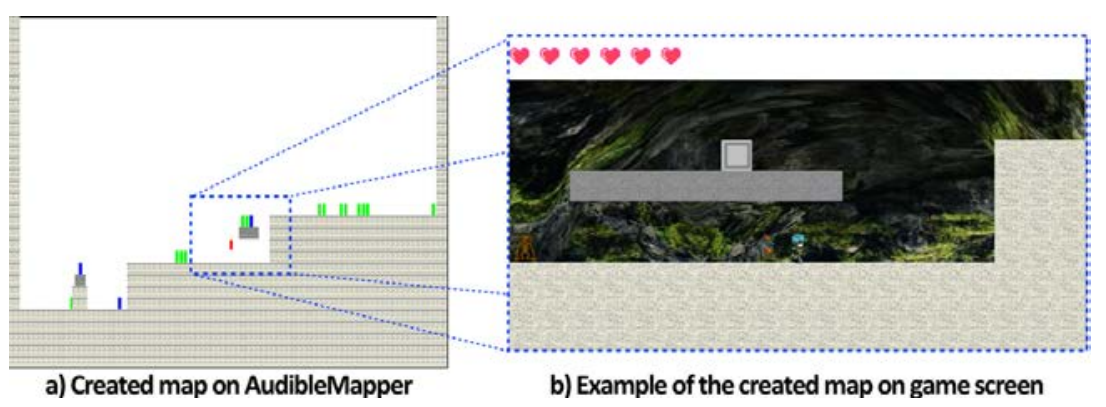

Fig. 2. An example of edited maps created with AudibleMapper (Left) and corresponding game field (Right)

the valley. Furthermore, we prepared a variety of gimmicks that our previous games did not contain, including movable scaffolds that the character can carry, footholds that move regularly, and rocks that decrease the health points of the character riding on them.

The player controls the character to avoid gimmicks with the jump control. The player battles against enemies and aims at the goal with the basic actions mentioned above. When two persons cooperatively play the game, one player mainly leads the game, while the other can freely move around and support his or her counterpart.

\subsection{Auditory and tactile information presentation}

Information on the screen is presented using various sounds and other effects, which are heard by connecting stereo speakers or headphones to the computer. All the objects, including enemy characters and bullets on the field, have at least four sound effects corresponding to their movement, action, attack, and annihilation. Static objects also have sound effects that indicate their existence. Gaining an understanding of the positional relationship between these objects and the player's character is possible using the interaural difference of acoustic volume between the left and right to indicate horizontal distance, as well as differences in sound pressure level to indicate vertical distance. Furthermore, dedicated sound effects were incorporated to prompt the user about the character's situation such as approach walls, scaffoldings, or a valley. We also implemented the aural "birds-eye" view function. This function enables the player to pause the game and aurally overview the positional relationship of the nearby scaffold or object using cursor keys.

Besides, connecting a dot matrix display (e.g., KGS Corporation DV-2) to the computer makes it possible for the users to recognize the game screen by touching the tactile display. All screen information, including positions of the objects and the player character, are provided by a binary means that varies depending on whether the location is up or down in relation to the pin. Such information is 
indicated in real time, enabling the player to easily and immediately discern the status of the screen.

\section{Conclusion}

In this article, we introduced an inclusive side-scrolling action game with high real-time performance and accessibility functions for visually impaired people, and it is available to play with more than one person. The significant feature of this game is the accessibility functions for blind gamers, such as scanning the current view by audio feedback and compatibility to tactile display. Our future work includes the improvement of game usability and the development of an integrated game development tool for the visually impaired.

\section{References}

1. Yuan, B., Folmer, E., Harris Jr., F.C., "Game Accessibility: A Survey," Universal Access in Information Society, 10, pp. 81-100, 2011.

2. Miesenberger, K., Ossmann, R., Archambault, D., Searle, G., Holzinger, A., "More Than Just a Game: Accessibility in Computer Games," Lecture Note in Computer Science, 5298, pp. 247-260, 2008.

3. Porter, J. R., Kientz, J. A., "An Empirical Study of Issues and Barriers to Mainstream Video Game Accessibility," Proc. ACM ASSETS '13, pp. 3:1-3:8, 2013.

4. Zahand, B., "Making Video Games Accessible: Business Justifications and Design Considerations," https://msdn.microsoft.com/en-us/library/windows/ desktop/ee415219 (v=vs.85) .aspx, (cited: 2017/04/17)

5. AudioGames.net http://www.audiogames.net/, (cited: 2017/04/17)

6. Matsuo, M., Miura, T, Sakajiri, M., Onishi J., Ono T., "Audible Mapper and ShadowRine: Development of Map Editor Using Only Sound in Accessible Game for Blind Users, and Accessible Action RPG for Visually Impaired Gamers," Lecture Note in Computer Science 9759, pp:537-544, 2016.

7. Matsuo, M., Miura, T, Sakajiri, M., Onishi J., Ono T., "Experience Report of a Blind Gamer to Develop and Improve the Accessible Action RPG ShadowRine for Visually Impaired Gamers," J. Tech. Persons with Disabilities, 5, 2017 (to Appear)

8. HSPTV!, http://hsp.tv/, (cited: 2017/04/17)

9. Morelli, T. Foley, J. Folmer, E., "VI-Tennis: a vibrotactile/audio exergame for players who are visually impaired," In Proc. FDG '10, pp:147-154, 2010.

10. Rector, K., Bennett, C. L., Kientz, J. A., "Eyes-free yoga: an exergame using depth cameras for blind \& low vision exercise", In Proc. ASSETS '13, Article No. 12 (8 pages), 2013.

11. Morelli, T. Foley, J. Folmer, E., "Vi-bowling: a tactile spatial exergame for individuals with visual impairments," In Proc. ASSETS '10, pp:179-186, 2010. 